\title{
Computational Determination of Alkaloid Chemical Shifts with pH Change
}

UCDAVIS

DEPARTMENT OF CHEMISTRY
Amy T. Bellinghiere ${ }^{1}$, Nicolle A. Doering ${ }^{2}$, Richmond Sarpong ${ }^{2}$, Dean J. Tantillo ${ }^{1}$

${ }^{1}$ University of California, Department of Chemistry, Davis, CA 95616

2University of California, Department of Chemistry, Berkeley, CA 94720

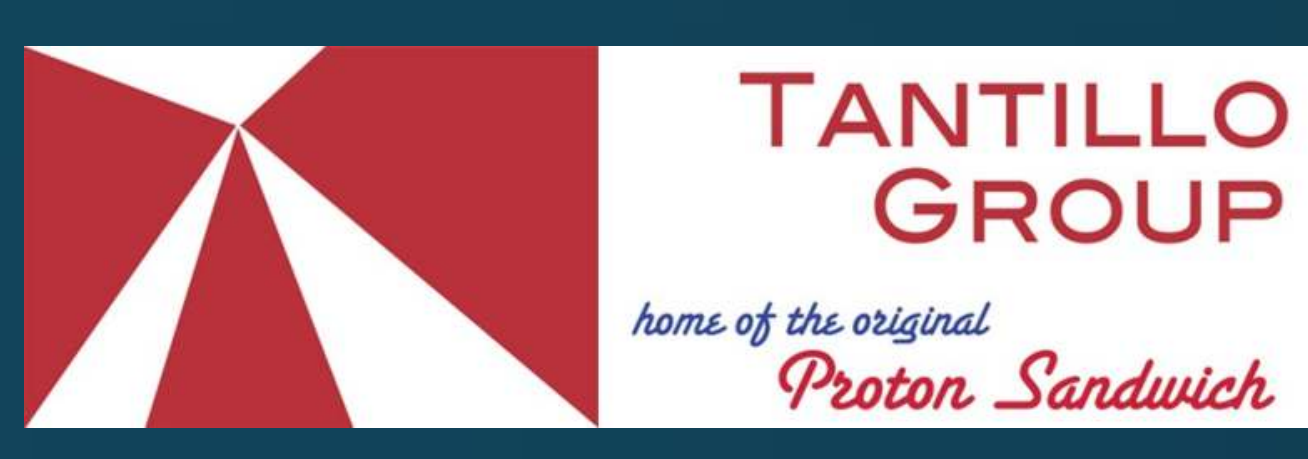

\begin{abstract}
Verifying that the structures of synthetic alkaloids match those of natural products is often challenging due to changes in ${ }^{1} \mathrm{H}$ and ${ }^{13} \mathrm{C}$ chemical shifts at different $\mathrm{pHS}$ of solutions used for recording NMR spectra. We are developing a computational method to determine the degree of protonation for alkaloids in solution by comparing the theoretical chemical protonation for alkaloids in solution by comparing the theoretical chemical
shifts for the ammonium and free base forms of alkaloids to the experimental shifts. While combining the theoretical shifts for the two forms of the alkaloids into a weighted average for comparison against the experimental shifts at a given pH creates a new set of chemical shifts closer to the experimental data, predicted shifts were not accurate enough to describe the experimental data. Thus, additional methods of modelling the protonated akaloids were investigated. DFT calculations were performed at the mPW1PW91/6-311+G(2d,p) (GIAO; PCM, chloroform)//B3LYP-D3(BJ)/6$31 \mathrm{G}+(\mathrm{d}, \mathrm{p})$ level of theory.
\end{abstract}

\section{Introduction}

${ }^{1} \mathrm{H}$ and ${ }^{13} \mathrm{C}$ NMR spectra from synthetic alkaloids are often difficult to match to the corresponding spectra for the natural products from literature.

Depending on the protonation state of the alkaloid in solution the chemical shifts can change drastically.,2 For example, Hugelshofer et al. recently published the total synthesis of (-)-daphlongamine $\mathrm{H}$ for which they reported chemical shifts for both the free base and ammonium form of the product against previously reported spectra of the natural product from two different sources. In this case, ${ }^{1} \mathrm{H}$ and ${ }^{13} \mathrm{C}$ NMR spectract readily available from the literature for both forms of the product. ${ }^{1}$

Aims of this work:

$>$ Collect experimental ${ }^{1} \mathrm{H}$ and ${ }^{13} \mathrm{C}$ NMR spectra for compounds $\mathbf{1}$ and $\mathbf{2}$ (Figure 1) over the course of an NMR titration with TFA to compare to theoretical chemical shifts.

$>$ Determine an accurate method for calculating percent protonation using ${ }^{1} \mathrm{H}$ and ${ }^{13} \mathrm{C}$ chemical shifts for an alkaloid.

$>$ Develop a method to weight ${ }^{1} \mathrm{H}$ and ${ }^{13} \mathrm{C}$ NMR chemical shifts for free base and ammonium forms of alkaloids from which weighted theoretical chemical shifts can be created to compare to experimental spectra collected at any $\mathrm{pH}$ of the NMR solution.

Accurately predict theoretical ${ }^{1} \mathrm{H}$ and ${ }^{13} \mathrm{C}$ chemical shifts for alkaloids with any degree of protonation.

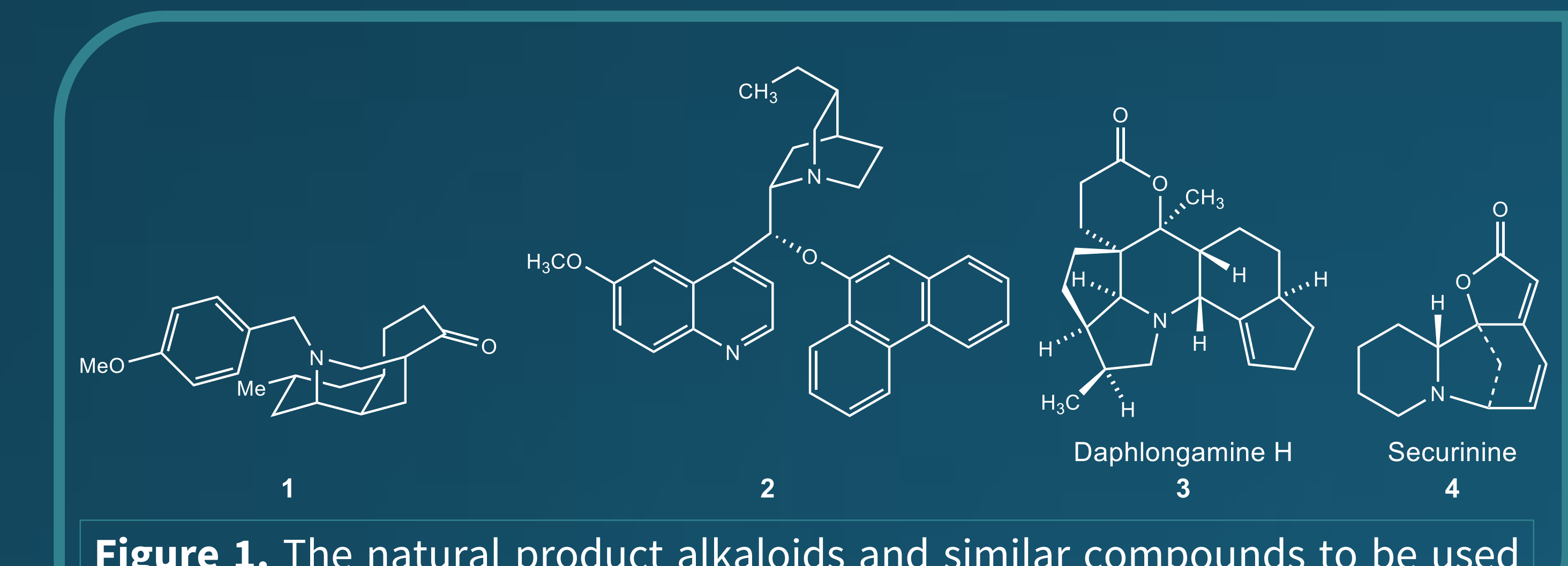

Figure 1. The natural product alkaloids and similar compounds to be used for calculating percent protonation.

\section{Methods}

Titration Method

TFA was added in 0.1 eq to a total of 2 eq to a solution of free base, $\mathbf{1}$ or $\mathbf{2}$, in $\mathrm{CDCl}_{3} .{ }^{1} \mathrm{H}$ and ${ }^{13} \mathrm{C}$ NMR spectra were collected every $0.1 \mathrm{eq} .{ }^{1} \mathrm{H},{ }^{13} \mathrm{C}$, COSY, and HSQC experiments were collected at the beginning and end of the titration (Figure 2).

\section{Computational Methods}

The chemical shifts for 1 were calculated using the mPW1PW91/6$311+\mathrm{G}(2 \mathrm{~d}, \mathrm{p})\left(\mathrm{GIAO} ; \mathrm{PCM}, \mathrm{CHCl}_{3}\right) / / \mathrm{B} 3 \mathrm{LYP}-\mathrm{D} 3(\mathrm{BJ}) / 6-31 \mathrm{G}+(\mathrm{d}, \mathrm{p})$ level of theory Gaussian09 was used to perform optimizations and NMR calculations. ${ }^{3}$ Conformational searching was performed with Spartan $10 .{ }^{4} \mathrm{~A}$ Boltzmannweighted average of conformers with a relative energy within $3 \mathrm{kcal} / \mathrm{mol}$ of the lowest energy conformer was used to calculate chemical shifts.

\section{Determining Degree of Protonation}

NMR Titration with TFA

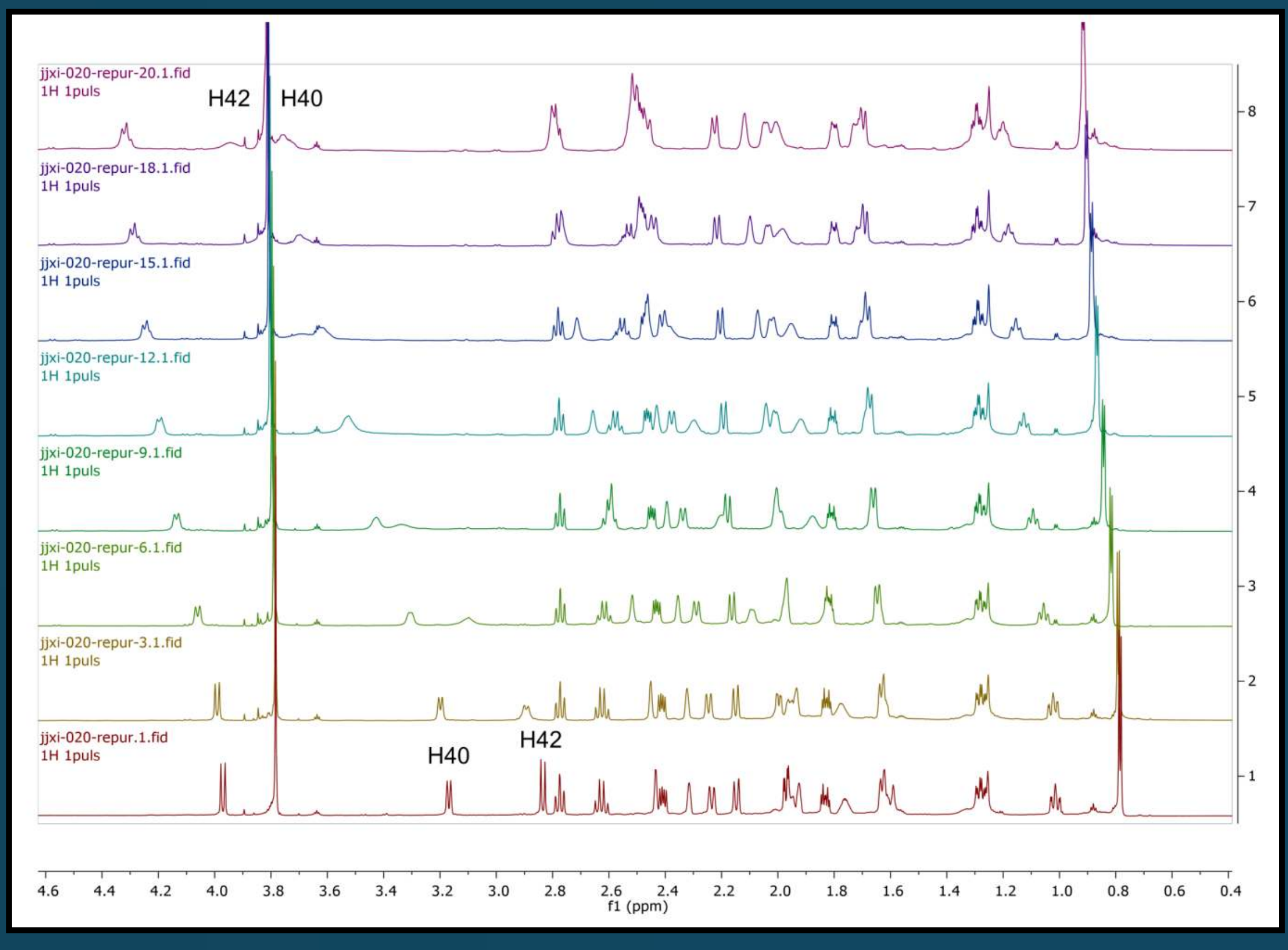

Figure 2. ${ }^{1} \mathrm{H}$ NMR spectra of compound 1 from $0-2.0$ eq TFA.

Calculate ${ }^{1} \mathrm{H}$ and ${ }^{13} \mathrm{C}$ NMR Chemical Shifts

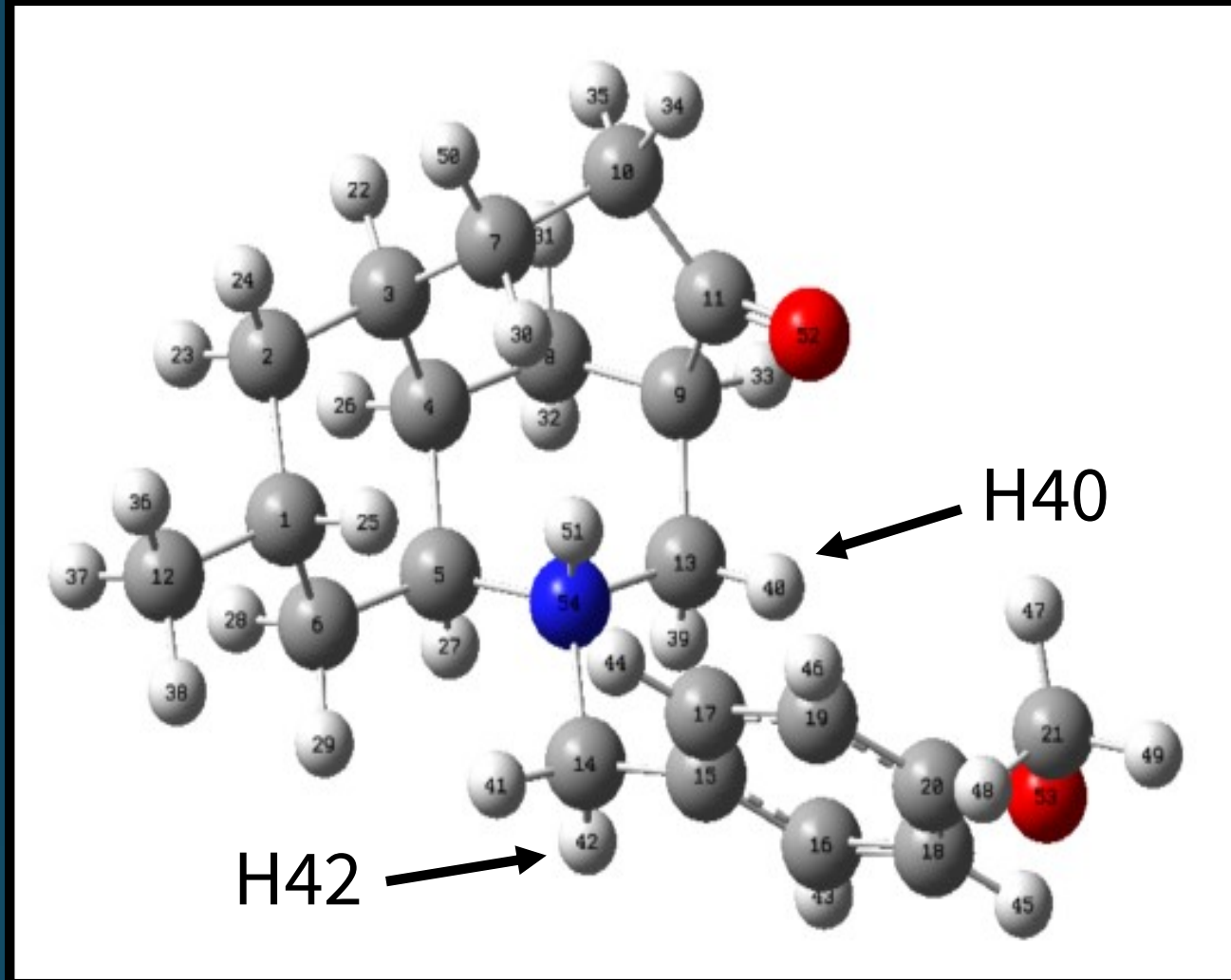

Figure 3. The lowest energy conformer of the ammonium ion of $\mathbf{1 .}$

Weighting of Free Base and Ammonium ${ }^{1} \mathrm{H}$ NMR $\delta$ 's

\begin{tabular}{|c|c|c|c|c|c|}
\hline \multirow{3}{*}{$\frac{\text { Comp. }}{\frac{\mathrm{H \#}}{\mathrm{H} 40}}$} & Exp. & Deprotonate & ate & htec & Exp. - Test \\
\hline & $\delta$ (ppm) & $\underline{\delta(p p m)}$ & $\delta$ (ppm) & $\delta$ (ppm) & Abs. Dev \\
\hline & 3.47 & 2.77 & 3.82 & 3.44 & 0.03 \\
\hline \multirow[t]{2}{*}{$\mathrm{H} 42$} & 3.42 & 2.71 & 3.82 & 3.42 & 0.00 \\
\hline & Weight: & 0.36 & 0.64 & MAD: & 0.02 \\
\hline
\end{tabular}

Table 1. The experimental and theoretical ${ }^{1} \mathrm{H}$ chemical shifts for $\mathrm{H} 40$ and H42 from compound $\mathbf{1}$. The experimental shifts were used to determine the weighing of the theoretical shifts for the free base and ammonium forms of compound $\mathbf{1}$ to create the test chemical shifts.

Degree of Protonation over the NMR Titration

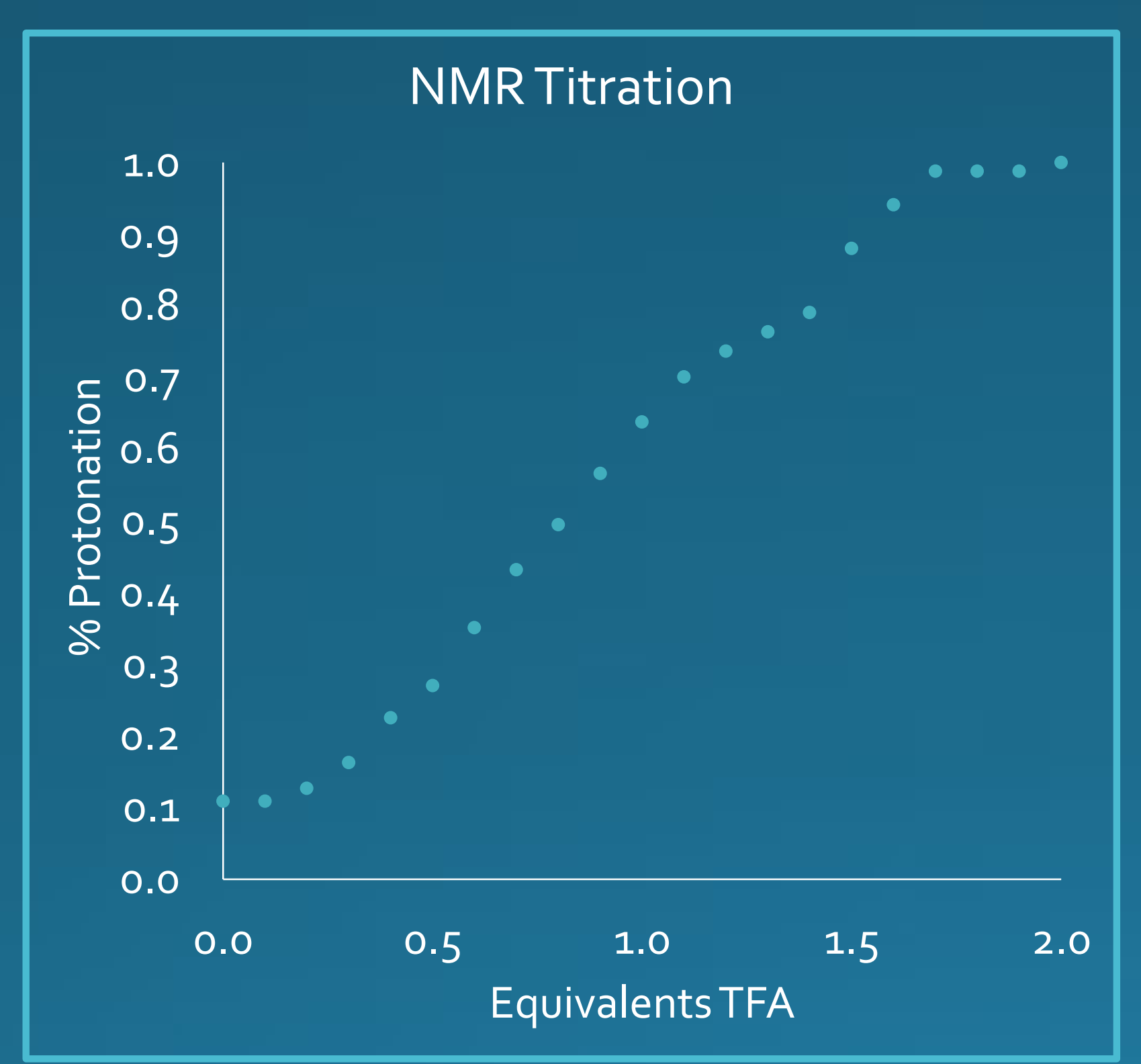

Figure 4. Degree of protonation of 1 throughout titration with TFA, weighing $\mathrm{H} 40 / \mathrm{H} 42(\mathrm{C} 13 / 14)^{1} \mathrm{H}$ shifts against experimental shifts.

\section{Results}

An initial trial to determine the degree of protonation over the course of the NMR titration for 1 , using the ${ }^{1} \mathrm{H}$ chemical shifts from two of the protons closest to the amine, H40 and H42 (Table 1), showed a steady increase in protonation from $\sim 10-100 \%$ (Figure 4 ).

$>$ The theoretical chemical shifts for the free base of compound $\mathbf{1}$ were accurate compared to the experimental shifts.

$>$ However, the theoretical chemical shifts for the ammonium ion, failed to meet the acceptable criteria for NMR prediction $\left(<0.3 \mathrm{ppm}\right.$ for ${ }^{1} \mathrm{H}$ NMR and $<7 \mathrm{ppm}$ for ${ }^{13} \mathrm{C} \mathrm{NMR}$ ) when compared to the chemical shifts at the end of the titration. ${ }^{3-6}$

Currently, different methods of computationally modeling the ammonium species of the alkaloids (Figure 5) are being tested to find an appropriate model for predicting ${ }^{1} \mathrm{H}$ and ${ }^{13} \mathrm{C}$ shifts in these cases. ${ }^{7.9}$

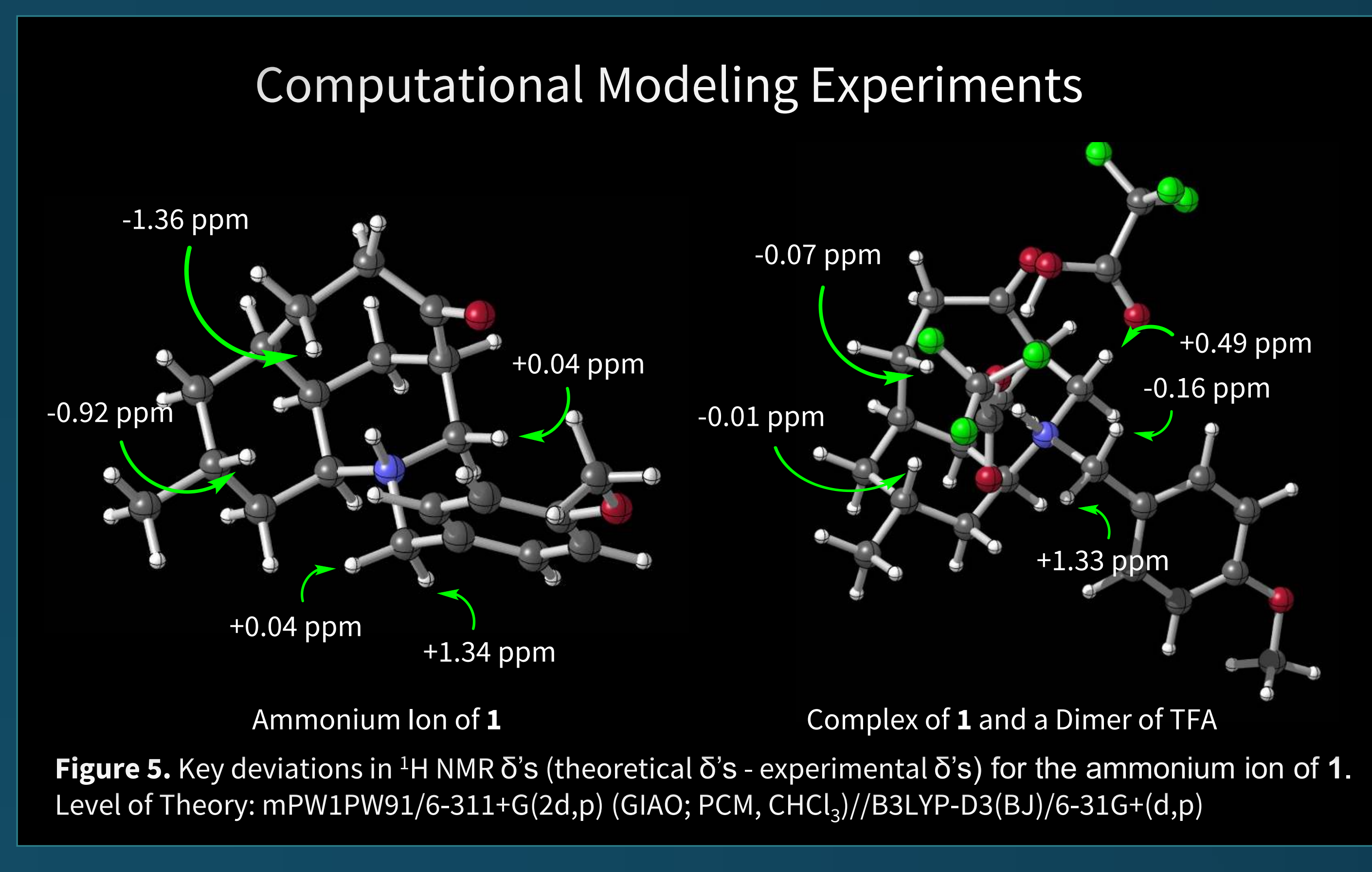

\section{Conclusions}

$>$ NMR titrations for two alkaloid-type compounds were performed to predict degree of protonation as $\mathrm{pH}$ decreased.

By comparing theoretical ${ }^{1} \mathrm{H}$ chemical shifts of the free amine and ammonium forms of 1 to the experimental shifts throughout the titration, a degree of protonation could be determined.

Future work, will be done to accurately predict all ${ }^{1} \mathrm{H}$ and ${ }^{13} \mathrm{C}$ chemical shifts for protonated alkaloids. Once these shifts can accurately be predicted, the ${ }^{1} \mathrm{H}$ and ${ }^{13} \mathrm{C}$ chemical shifts for the deprotonated and protonated forms of these compounds will be used to calculate the degree of protonation for compounds $\mathbf{1}$ and $\mathbf{2}$ over the course of the titration and for alkaloids in NMR solutions from previously reported spectra.

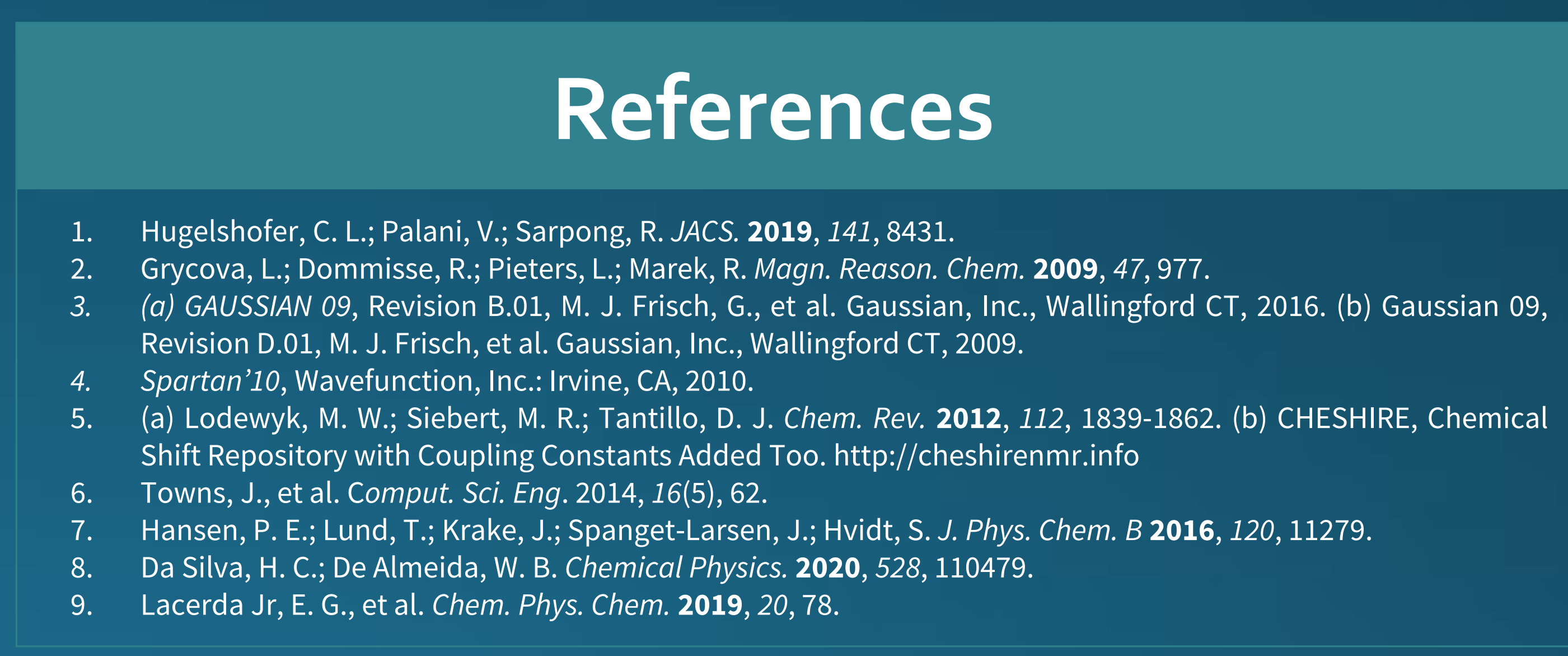

\section{Acknowledgements}

This work used the Extreme Science and Engineering Discovery Environment (XSEDE), which is supported by National Science Foundation grant number ACl-1548562 resource Comet at the SDSC through allocation TGCHE050017N.

\section{XSEDE}

